\title{
Space "phobia": a pseudo-agoraphobic syndrome
}

\author{
I S A A C M A R K S \\ From the Institute of Psychiatry, London
}

SUMMARY Space phobia in 13 patients is described with features distinct from agoraphobia. Its hallmark is fear of absent visuospatial support (open spaces) and of falling, unlike the fear of public places found in agoraphobia. Other distinctions are the much later mean age of onset (55 years compared with 24 years), rarity of depression or free floating anxiety, limited response to treatment by exposure in vivo, and the frequent presence of diverse neurological and cardiovascular disorders which can progress until the patient is confined to a wheelchair. Space phobia may indicate disturbed integration of vestibulo-ocular reflexes due to diverse lesions in the neck or more centrally. Better understanding of the pathogenesis may illuminate how anxiety produces some physical symptoms.

In 1976 four cases were published who had an unusual fear of open space dependent on visuospatial rather than kinaesthetic or height cues. ${ }^{7}$ Clinical features were gross exaggeration of phenomena often found to a mild degree in agoraphobia, and the mean age of onset was 30 years later than that of agoraphobia. Nine more similar cases are presented here, and their features summarised. These suggest that space "phobia" is not an agoraphobic variant, but rather a pseudoagoraphobic syndrome of diverse causes, of ten organic with a disturbance of balance, which is fairly resistant to the exposure treatment that helps so many agoraphobics. ${ }^{3-5}$

\section{Description of syndrome}

This is based on the 13 patients summarised in table 1 , the first four of which were described by Marks and Bebbington. ${ }^{7}$ The characteristic feature of "space phobia" shown by the 13 patients was intense fear evoked by visuospatial cues, with severe disturbance of walking in 11 and of driving in two. In the 11 whose walking was affected, it was striking that at least in the early stages, actual physical support was not usually ncessary, only visual support nearby. As patient five said "I need to be closed in while I'm walking. The fear is the space around me." One patient abolished the unsteadiness by closing her eyes (case 4). Patients did not need to touch such support to maintain balance, though they of ten did cling to it. They commonly crawled on the floor to cross a room, or walked close to walls or hedges in streets. All but one were afraid of falling - the exception (case 9) felt

Address for reprint requests : Prof Isaac Marks, Institute of Psychiatry, de Crespigny Park, London SE5 8AF

Accepted 29 December 1980 pulled to the right while driving, and had found herself on the wrong side of the road. One patient could hardly walk yet rode a bicycle normally (case 10), another could dance on a crowded dance floor but had to leave if the crowd left (case 4), another only felt all right if his eyes were absolutely still (case 7), while another who fell repeatedly did not learn to protect her face by stretching out her arms (case 6). The disability was often crippling, and both male patients had lost their jobs. Exacerbations commonly began after falls superimposed on earlier disability, another worsened after her car overturned and three others during a time of family illness. The disorder progressed in several patients until they were confined to a wheelchair even indoors.

Details of two patients follow to illustrate the syndrome.

Case 5 This patient was aged 68 years when referred in 1977. She has not been out alone for six years. As a child she had "walked badly" and balanced poorly. She had had two bad falls, at age 44 years, fracturing her right ankle, and at age 54 years, fracturing her left humerus. Her space phobia began in September 1970, after her husband was admitted to hospital for a detached retina. She experienced panic with fear of falling while walking, crossing roads, and getting up stairs, and of ten crawled about the house. She could walk unaided early in the morning but got worse as the day wore on. Three months later whilst shopping she was unable to turn to the right or later to cross a road, had to be helped by passers-by, took a taxi home and thereafter could only go out shopping accompanied and with an umbrella for support. In May 1971 , a few days after her son's wedding she became restricted to just crawling around the house and developed a septic sore on her knee. In June 1973 she noted slight giddiness when suddenly turning her head to the right, a "weak bladder," and pain across her shoulders and lower spine. A neurologist found a bruit 


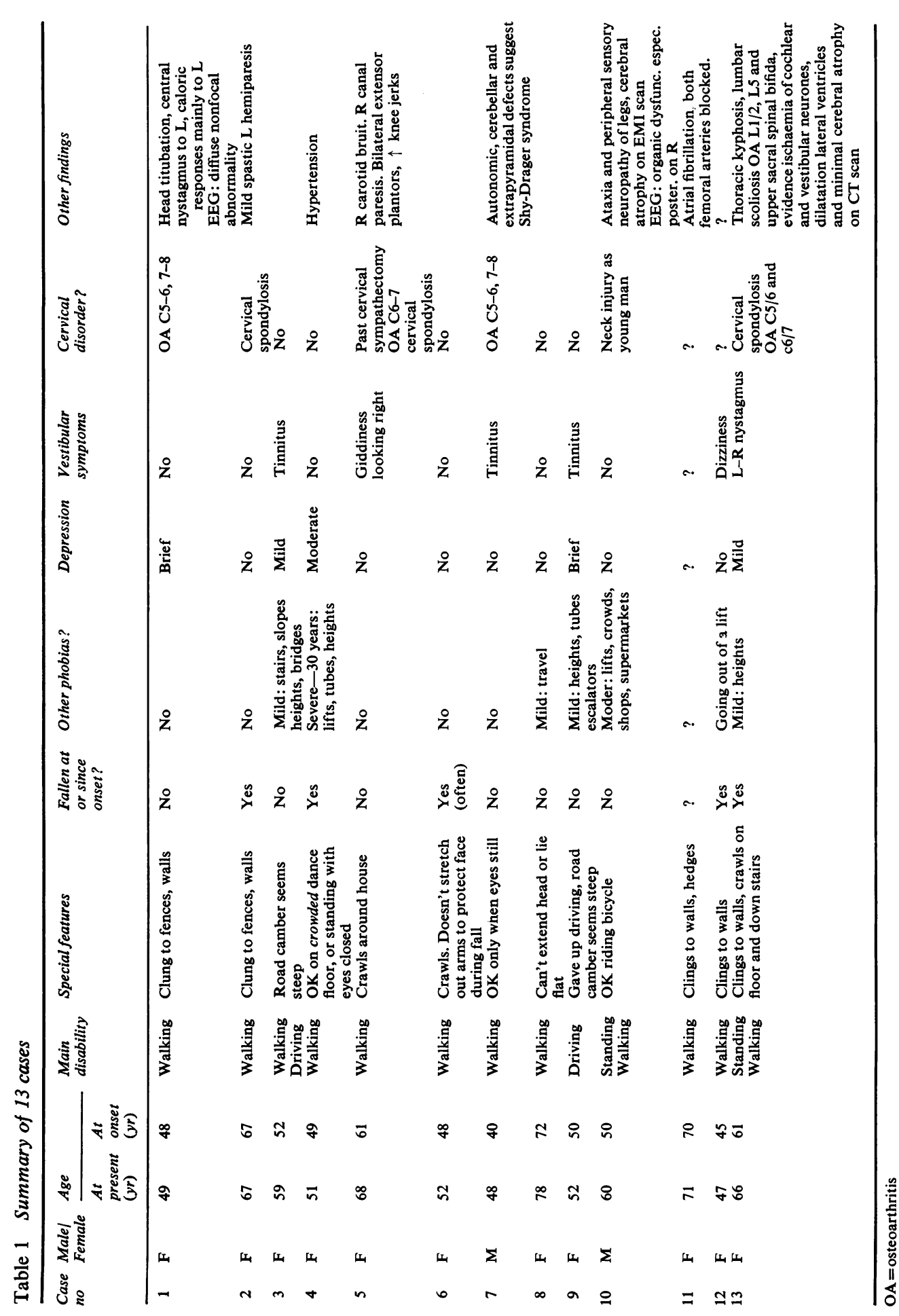


over her right carotid artery, and he thought she had a mild right vestibular lesion probably due to vertebrobasilar artery insufficiency. In July 1973 with walking exercises she improved to the point of walking with minimal contact, but never completely unaided, or outside. In April, 1976 after one friend was killed in a road accident and another became ill her difficulty in getting around the house again increased. Further graded exposure led to limited improvement at home only. She was re-referred as "an elderly agoraphobic" in November 1976 to a day hospital. She was preoccupied with the "awful sensation in my spine." She improved with a strict exposure programme in which she was not allowed to be wheeled around by patients and staff, and had to walk to the dining room. At the time she was cheerful, cooperative, placid and had normal cognition. In July 1978 she was found to have depressed triceps jerks, bilateral extensor plantars and increased knee jerks but very good power, radiological signs of cervical spondylosis at C6-7, and a right canal paresis. Her walking difficulty was out of all proportion to the neurological deficit, and fluctuated depending on her morale, on the proximity of help, and whether she was inside or outside her home.

The patient came from a stable background, had been married for 41 years, lived with her husband, and socialised with many friends and neighbours, who helped with shopping. She had had a cervical and lumbar sympathectomy for chilblains at age 39 years, radiation menopause and removal of fibroids (polymenorrhoea) at age 46 years, and a Manchester repair at age 59 years.

Case 8 was aged 78 years when referred. Though "always" reluctant to travel alone, this did not lead to avoidance and in the past she had travelled extensively. Six years earlier she had suddenly developed a sensation of falling, took prochlorperazine maleate and recovered completely after six months. Her space phobia began when aged 76 years after she fell in her front garden and fractured some ribs. Its features were intense feelings of being about to fall as she stood or walked without visual support nearby, unless she was immediately next to a wall, chair or railing. She avoided going out alone, and could not cross a space of $2 \mathrm{~m}$ outside her flat to reach her dustbin. She was unable to shop or to cross a street or to walk without holding onto somebody or something. With support she was able to get around freely. Within the confines of her flat and its courtyard she could walk unaided. Her "giddiness" increased drastically with even slight wind. She was unable to extend her head or to lie flat because this provoked unpleasant "giddiness"; this led to discomfort at hairdressers and to her being propped up at night. Oxazepam did not help while prochlorperazine maleate did slightly. The patient had had no previous illnesses, had a stable personality, and led an active social life. Examination showed a delightful, forthright, resilient, spry, fit old lady with normal orientation and mood and no free floating anxiety. She would not lie flat nor allow her head to be extended, nor be put in the critical position to test for benign positional vertigo. Physical examination was otherwise normal. Treatment failed. It consisted of 16 sessions ( 20 hours) of graduated walking practice across rooms, spaces and home; sometimes she crossed spaces of up to 20 feet wide unaided, and in other sessions could not even make a start. Anxiety was linked to the intensity of dizziness. During imaginal exposure anxiety diminished, but this did not transfer to real life. Paradoxical intention had no effect.

\section{Discussion}

Distinction of "space phobia" from agoraphobia This is now clear on seven grounds (table 2). (1) the mean onset age of the 11 space phobics was 54 years, some 30 years later than for agoraphobia, ${ }^{6}$ and none began before age 40 years. (2) agoraphobic features, when present, commonly began long before the space phobia did, and were disproportionately much milder than the space phobia. Fears of public places which are the hallmark of agoraphobia for example, public transport, crowds, heights or lifts, were noted in five of the patients, but only two consistently avoided such situations, (3) and (4) both fear of falling and fear of open space without visual support is usually mild or absent in agoraphobia, whereas they are the central feature of space phobia, (5) agoraphobia usually responds well to exposure treatment, while space phobia seems more resistant. It was tried in nine cases, but their improvement was fragile, with liability to rapid relapse, (6) agoraphobics commonly have other psychiatric problems, including depression, free floating anxiety and personality difficulties. In contrast, space phobia was associated with a stable personality in all but one case, and other neurotic symptoms were uncommon, bar the mild fears already noted. Although five patients had had past depression leading to treatment in four, in only two was sufficient depression present to receive antidepressant treatment at the time of consultation for the space phobia. Two patients had close relatives with senile dementia.

Table 2 Features distinguishing space phobia from agoraphobia

\begin{tabular}{llll}
\hline & & Space phobia & Agoraphobia \\
\hline 1 & Onset age & Old (mean 55yr) & Young(mean 25yr) \\
2 & Fear of public places & Mild/absent & Mod/severe \\
3 & Fear of open spaces & Mod/severe & Mild/absent \\
4 & Fear of falling & Mod/severe & Mild/absent \\
5 & $\begin{array}{l}\text { Response to exposure } \\
\text { in vivo }\end{array}$ & Slow, fragile & Good \\
6 & $\begin{array}{l}\text { Depression, free floating } \\
\text { anxiety }\end{array}$ & Unusual & Common \\
7 & \begin{tabular}{l} 
Organic features \\
\hline
\end{tabular} & Usual & Rare \\
\hline
\end{tabular}


Organic features This seventh distinctive feature is usual in space phobia, but rare in agoraphobia. Neurological and/or cardiovascular symptoms or signs occurred in 10 of the 13 patients, though none complained of vertigo. Three had tinnitus, five had cervical spondylosis and one a history of neck injury. In case 1 radiological signs of cervical spondylosis were associated with head titubation, central nystagmus to the left, caloric responses showing directional preponderance to the left, and diffuse non-focal abnormality on the EEG-she was thought by a neurologist to have a lesion at or above the vestibular nucleus. In case 2 a mild spastic hemiparesis was attributed to cervical spondylosis. Cases 3 and 9 had tinnitus alone, and case 4 hypertension. Case 5 had giddiness on looking right, a bruit over the right carotid, bilateral extensor plantars and increased knee jerks, radiological signs of cervical spondylosis and a right canal paresis; she was thought by a neurologist to have vertebrobasilar artery insufficiency. In case 7 tinnitus and cervical spondylosis were associated with autonomic, extrapyramidal and cerebellar deficits. In case 10 the history of neck injury was associated with ataxia and sensory neuropathy of the legs, plus CT scan signs of cerebral atrophy, and an EEG suggestive of diffuse brain dysfunction. Case 11 had atrial fibrillation and blockage of both femoral arteries. Case 13 had left-right nystagmus, cervical spondylosis with osteoarthritis of $\mathrm{C} 5 / 6, \mathrm{C} 6 / 7, \mathrm{L1} / 2$, kyphoscoliosis, spinal bifida occulta at L5 and the upper sacrum, evidence of ischaemia of cochlear and vestibular neurones, dilation of the lateral ventricles and minimal cerebral atrophy on CT scan.

\section{PATHOGENESIS OF SPACE PHOBIA}

All the patients apparently had some ocularvestibular disturbance, whose genesis could vary greatly. Three main origins can be consideredcervical, central neurological, and anxiety.

1 Cervical Five of the patients had cervical spondylosis and another had a history of neck injury. Cervical spondylosis is, of course, common enough without symptoms, even when osteoarthritic spurs narrow the space in which the vertebral arteries lie. However, if one vessel is hypoplastic, stenosed or occluded through atherosclerosis, then movements of the head to one side can precipitate vascular insufficiency and neurological symptoms. ${ }^{5}$ The same can occur from bony anomalies of the cervical spine, from cervical ribs and from fibrous bands linking ribs to vertebra, and from muscle slip insertions at $\mathrm{C}_{6} \cdot{ }^{10} \mathrm{~A}$ sense of instability can also be engendered by lesions in the cervical spinal ligaments, such as can follow neck injury (Isaacs, personal communication). The segments C6-7 may be low for involvement of tonic neck reflexes, but systematic study of the effect of manipulation of the position of the head on space phobia, nystagmus, EEG, and EMG of muscles of the trunk, neck and arms would be worthwhile (Miller, personal communication). Whether cervical sympathectomy affects balance in old age is not known. 2 Central neurological Outside the neck many neural pathways might contribute to space phobia, as in cases 1 and 6. Hood (personal communication) has found in similar cases exaggeration of nystagmic responses implying derangement of the vestibulo-ocular reflex. This was revealed by testing in darkness and in the presence of optic fixation. Pursuit movements were also usually deranged in light but normal when following a light target in total darkness, whereas in the normal subject there is usually little difference between the two conditions. Hood wondered whether space phobia might result from derangement of the integration mechanism at a cerebellar level between the peripheral visual input and foveal input; tests suggested for carrying out in future cases were observations of optokinetic nystagmus, pursuit movements with and without a background, vestibular tests with and without fixation, and tests of vestibulo-ocular reflex suppression.

The routine maintenance of equilibrium centrally involves at the least the reticular formation, cerebellum and vestibular nuclei forming a closeknit functional group, and peripheral input from the labyrinth, neck, eyes and other parts of the body. ${ }^{9}$ Roberts suggested (personal communication) that the fear of falling in these patients might be associated with inappropriately generated rescue reactions, and these can be disturbed in basal ganglia disease. ${ }^{9} \mathrm{He}$ wondered whether eyeball rotation of central, spurious, origin could give rise to some of the symptoms found in "space phobia", and suggested as a possible test asking future subjects to report the relative apparent movement of small, well-separated, visual targets in an otherwise darkened room. If one visual target is fixated, eyeball rotation should produce apparent movement of another target set some $15-20^{\circ}$ out in the periphery.

3 Anxiety Five of the cases $(2,4,6,12$ and 13) began after or were greatly aggravated by a fall. Space phobia might be related to a condition of ten seen after falls in old age, ${ }^{2}$ when patients became frightened of further falls, clutch at any object without regard to its value as a source of support, 
and often walk on their heels rather than their forefoot. Occasional patients fail to make corrective movements of their upper limbs when falling and go on rapidly to become immobile (as case 6 here). We found that many of these symptoms could be helped by rehabilitation or by providing minimal support, and thought the disturbance of visuospatial perception and movement pattern is aggravated by anxiety. The question arises why extreme anxiety on walking after a fall is so common in old age but not in younger age groups; young children fall regularly without becoming anxious. Contributory factors to anxiety in the elderly may be poorer agility and greater risk of fractures, loss of righting reflexes due to neuronal fallout, and focal neurological damage. Anxiety then becomes realistic.

In five of these patients their symptoms began or were made worse during periods of life stress or depression (cases 1, 4, 5, 6 and 12). Anxiety seemed more a modifying than a fundamental factor in genesis of the disturbance. In keeping with this, prolonged graded walking exercises were of more variable value in the present patients than similar exposure treatment is in agoraphobia. Space phobia exemplifies the synergy of physical and psychological factors. In present cases the phobia was disproportionate to demonstrable organic pathology. There is a wide range of reactions to disability. Some may be due to physical deficits hidden from clinicians. Others might result from anxiety which is less or more realistic, and not be associated with any previous history of neurotic reactions. Though the terms "physical" and "organic" on the one hand, and "psychological," "functional" and "neurotic" on the other are usually thought of as dichotomous, they have a wide area of overlap.

\section{Why space "phobia"?}

The hallmark of the syndrome is that perception of unsupported space leads to a fear of falling and inappropriate rescue reactions. An alternative term "Falling phobia" would not include the two patients whose main fear was space and depth cues while driving. All who are afraid of falling are not space phobic, and not all phobics fear falling. In some cases, space phobia is a transient phase in a developing disorder of balance which progresses to the point where the patient finds it almost impossible to stand unaided even in the presence of visuospatial cues.

Space phobia is sometimes mislabelled as agoraphobia. It could be called pseudoagoraphobia, which is separate from agoraphobia, though they presumably involve some overlapping physiological mechanisms. In agoraphobia fear of public places is a central feature, and dizziness (not vertigo) is common, while fear of open space is an inconstant minor characteristic and falls are very rare. Agoraphobia has been called "platschwindel"1 and attributed to a labyrinthine disorder ${ }^{8}$ while other young patients have been described with anxiety and vestibular type symptoms. ${ }^{10}$ The author has seen a woman age 60 years with agoraphobia plus a tendency to veer to the right while walking out of doors, but without any space phobia. Investigation of the pathogenesis of space phobia might indicate mechanisms by which many anxiety symptoms are expressed for example dizziness, fears of falling, and the normal fears generated by specific visuospatial and kinaesthetic cues such as fears of a visual cliff, of looking up at a skyscraper, and of the total absence of spatial cues. ${ }^{6}$

Many thanks are due to the following for drawing attention to and supplying detailed information about cases: Prof A Lishman (cases 1 and 13), Dr RTC Pratt (case 1), Prof CD Marsden (cases 7 and 10), Dr Ian Brockington (case 5), Dr L Solyom (case 6), Dr DR Sinclair (case 11), and Dr NN Seif (case 12), and to Profs B Isaacs, A Lishman, D Marsden, and JSG Miller, and to Drs JD Hood, M Ron, TD Roberts and B Toone, for their valuable comments.

\section{References}

1 Benedikt $M$. Allgemeine Wiener medizinische Zeitung 1870; 15:488.

2 Isaacs B. Recent Advances in Geriatric Medicine. Vol 1. Edinburgh: Churchill Livingston, 1978.

3 Lancet, Editorial 1979; 2:237.

4 Marks IM. Exposure Treatments: Chapters 7 and 8, p 163-242. In: Agras WS ed. Behavior Modification, 2nd ed. Boston: Little Brown and Co, 1978.

5 Marks IM. Behavioral psychotherapy of adult neurosis. In: Garfield S, Bergin AE eds. Handbook of Psychotherapy and Behavior Modification, 2nd ed. New York: John Wiley, 1978.

6 Marks IM. Fears and Phobias. London: Heinemann Medical, 1969

7 Marks IM, Bebbington P. Space phobia: syndrome or agoraphobic variant? Br Med J 1976; 2:345-7.

8 Pratt RTC, McKenzie W. Anxiety states following vestibular disorders. Lancet 1958; 2:347-9.

9 Roberts TDM. Neurophysiology of Postural Mechanisms, 2nd ed. Sevenoaks: Butterworths, 1978.

10 Toole JF. Cerebrovascular Disorders. Vertebralbasilar artery syndrome. New York: McGrawHill, 1967; 141-52. 